\title{
The effect of maternal and child early life factors on grade repetition among HIV exposed and unexposed children in rural KwaZulu-Natal, South Africa
}

\author{
J. M. Mitchell ${ }^{1,2}$, T. J. Rochat ${ }^{1,3,4 *}$, B. Houle ${ }^{5,6,7}$, A. Stein ${ }^{3,7}$, M. L. Newell ${ }^{1,8}$ and R. M. Bland ${ }^{1,7,9}$ \\ ${ }^{1}$ Africa Centre for Health and Population Studies, University of KwaZulu-Natal, South Africa \\ ${ }^{2}$ Department of Psychology, Stellenbosch University, Stellenbosch, South Africa \\ ${ }^{3}$ Section of Child and Adolescent Psychiatry, Department of Psychiatry, University of Oxford, Oxford, UK \\ ${ }^{4}$ Human Sciences Research Council, South Africa \\ ${ }^{5}$ Australian Demographic and Social Research Institute, The Australian National University, Canberra, Australia \\ ${ }^{6}$ Institute of Behavioral Science, University of Colorado at Boulder, Boulder, Colorado, USA \\ ${ }^{7}$ School of Public Health, University of Witwatersrand, Johannesburg, South Africa \\ ${ }^{8}$ Faculty of Medicine, Faculty of Social and Human Sciences, University of Southampton, Southampton, UK \\ ${ }^{9}$ Royal Hospital for Sick Children and Institute of Health and Wellbeing, University of Glasgow, Glasgow, UK
}

Receiving an education is essential for children living in poverty to fulfil their potential. Success in the early years of schooling is important as children who repeat grade one are particularly at risk for future dropout. We examined early life factors associated with grade repetition through logistic regression and explored reasons for repeating a grade through parent report. In 2012-2014 we re-enrolled children aged 7-11 years in rural KwaZulu-Natal who had been part of an early life intervention. Of the 894 children included, $43.1 \%$ had repeated a grade, of which $62.9 \%$ were boys. Higher maternal education (aOR 0.44; 95\% CI 0.2-0.9) and being further along in the birth order (aOR 0.46; 95\% CI 0.3-0.9) reduced the odds of grade repetition. In addition, maternal HIV status had the strongest effect on grade repetition for girls (aOR 2.17; 95\% CI 1.3-3.8), whereas for boys, it was a fridge in the household (aOR 0.59; 95\% CI 0.4-1.0). Issues with school readiness was the most common reason for repeating a grade according to parental report $(126 / 385,32.7 \%)$, while school disruptions was an important reason among HIV-exposed boys. Further research is needed to elucidate the pathways through which HIV affects girls' educational outcomes and potentially impacts on disrupted schooling for boys. Our results also highlight the importance of preparation for schooling in the early years of life; future research could focus on gaining a better understanding of mechanisms by which to improve early school success, including increased quality of reception year and investigating the protective effect of older siblings.

Received 2 July 2015; Revised 31 August 2015; Accepted 8 September 2015; First published online 9 October 2015

Key words: early life factors, grade repetition, HIV exposure, South Africa

\section{Introduction}

Millions of children in low- and middle-income countries (LMICs) fail to develop to their full cognitive potential. ${ }^{1}$ There is robust evidence that investments in early childhood development (ECD) are vital for children to fulfil this potential. Consequently, there has been strong support for strategies aimed at reducing risk factors and promoting protective factors for ECD in LMICs. ${ }^{2}$ Important risk factors which need to be addressed are malnutrition, stunting and childhood disease such as HIV, while factors which have been positively associated with child development include sustained exposure to breastfeeding and higher maternal education. ${ }^{1}$

While early childhood investments are key, middle childhood and the transition into formal schooling is also a critical developmental time for children and has been shown to impact

*Address for correspondence: T. J. Rochat, Africa Centre for Health and Population Studies, University of KwaZulu-Natal, South Africa.

(Email trochat@africacentre.ac.za) on their long term educational success. ${ }^{3}$ For example in both high-income countries (HICs) and LMICs, children who repeat the first grade of school are significantly more likely to experience academic disengagement and dropout in later years, ${ }^{4,5}$ which is, in turn, linked to poorer health and economic outcomes in adulthood. ${ }^{6,7}$ Understanding the factors that drive early failures in children's schooling is critical to the development of targeted interventions to improve children's educational outcomes, ${ }^{8,9}$ particularly in the context of poverty.

Important early factors were identified in two longitudinal studies from the United States which examined the association between early child and maternal factors and grade repetition. The first included a nationally representative sample of 996 children, aged 7-17 years, and found poverty, male sex, child behaviour problems and low maternal education to be associated with increased grade repetition, while higher maternal education and residing with both parents reduced the risk of grade repetition. ${ }^{10}$ A more recent longitudinal study in the United States with a sample of 220 low-income primary school-aged African-American 
children, ${ }^{11}$ found a lack of stimulation at home before school enrolment and high externalizing behaviour (related to aggressive and criminal behaviour), ${ }^{12}$ to be significantly associated with increased likelihood of grade repetition.

These studies did not examine the effect of the broader familial context, such as the effect of having older siblings, which has been suggested to be as important as parental contribution to younger children's cognitive development and consequent schooling outcomes. ${ }^{13}$ Furthermore, the effect of having had exposure to crèche and reception year, which have been shown to be important in promoting ECD, were not included. ${ }^{14}$ Importantly, the effect of HIV infection or exposure, which is of particular importance in high HIV prevalence settings, was not examined. A critical review of global literature on HIV-exposed children's educational outcomes ${ }^{15}$ mostly focused on orphaned children and reported poorer educational outcomes among HIV-orphaned than non-orphaned children, ${ }^{16,17}$ with particularly strong effects on girls. ${ }^{18-20}$ This review elucidated several gaps in the literature including a tendency to focus on already orphaned children without examining effects on schooling before parental death; few data on sex differences; and a lack of longitudinal studies. Most studies have also focused only on school enrolment and attendance, ${ }^{16,21,22}$ or failure in later stages of schooling among adolescents, ${ }^{16,23}$ with little research focusing on grade repetition, or earliest grade failure.

In South Africa, some research has examined early school factors associated with grade repetition across the primary school years. ${ }^{24,25}$ However, to our knowledge, no studies have examined whether early life exposure to maternal HIV infection influences grade repetition among children in the early years of schooling, and if exposure to reception year and current familial factors mediate these effects. ${ }^{26}$

The primary aim of this research was to investigate early life factors associated with earliest repeated grade, and to explore child characteristics and parental report of reasons for failure among early repeaters. We examined this question in a well-established cohort using a longitudinal design including children exposed to HIV in fetal life or childhood, and HIV-unexposed children in rural South Africa.

\section{Methods}

\section{Setting}

This research took place at the Africa Centre for Health and Population Studies (Africa Centre), in Northern KwaZuluNatal, South Africa, a predominantly rural area with one of the highest prevalence of HIV worldwide. ${ }^{27}$ A successful large scale Prevention of Mother-to-Child Transmission programme and HIV treatment programme, providing free drugs and clinical care, have been operating in the district since the early 2000 s. $^{28,29}$

\section{Participants}

The sample consisted of children aged 7-11 years, who were born, and currently reside in, the study area of the Africa Centre. All children were part of an early life intervention to support exclusive breastfeeding (EBF), the Vertical Transmission Study (VTS). ${ }^{30,31}$ This was a non-randomised, prospective, intervention cohort study (2001-2006), that supported mothers to exclusively breastfeed and followed children from birth to 2 years of age.

\section{Procedures}

Data collected in the VTS included maternal HIV status during pregnancy, maternal education, income source, socioeconomic status at the time of the child's birth and daily infant feeding practices collected at weekly intervals in the first 6 months postnatally. ${ }^{30,31}$ Household ownership of a fridge was used as a proxy for socioeconomic status (SES), as is common in other research in LMICs. ${ }^{32}$

In 2013/2014 we re-enrolled HIV-negative children from the VTS to investigate the impact of this early life intervention on their longer term development, in the 'Saving Brains Cohort'. Inclusion criteria for re-enrolment included that the mother and child were alive, the child was still residing in the research area, the mother's HIV status in pregnancy was known, and the child was HIV-negative.

While children's mothers had to be alive to be included in the Saving Brains cohort, they did not have to currently reside with the mother; children were still eligible if they resided with an alternative caregiver. Children and their mothers and/or caregivers were visited three times by field staff, all of whom had at least 4 years' experience collecting research data. In Visit 1 consent to enrol (also from alternative caregiver if applicable), basic demographics and whether the mother met the inclusion criteria were measured. In Visit 2, data were collected from the primary caregiver (mother or other) about the child's schooling history and repeated grades, and mothers/caregivers completed both the Competence Scale and the Behaviour Rating Scale of the Child Behaviour Checklist (CBCL), which has been validated in a variety of cultural settings. ${ }^{17,33}$ The Competence Scale includes parent ratings of children's social and peer relationships, their level of independence and their performance on specific academic subjects. It also collects qualitative descriptive data on parental understandings of reasons for children's failure in school or other problems the child may be experiencing. In Visit 3, the Kaufman Assessment Battery for Children, second edition (KABC-II) was administered to measure children's cognition. Using the Luria approach a global score called the Mental Processing Index (MPI), which is reflective of the child's global intelligence, was determined. The KABC-II has been shown to be a valid measure of cognition in LMICs. ${ }^{34,35}$

Figure 1 illustrates the data collected and used in this analysis, and how we developed an early life factor model and additional models of predictors of repeat grade.

\section{Definitions}

\section{Repeat school grade}

In South Africa school starts at age 5 in Grade R (reception class), and finishes with Grade 12 and includes several phases: Grade R 


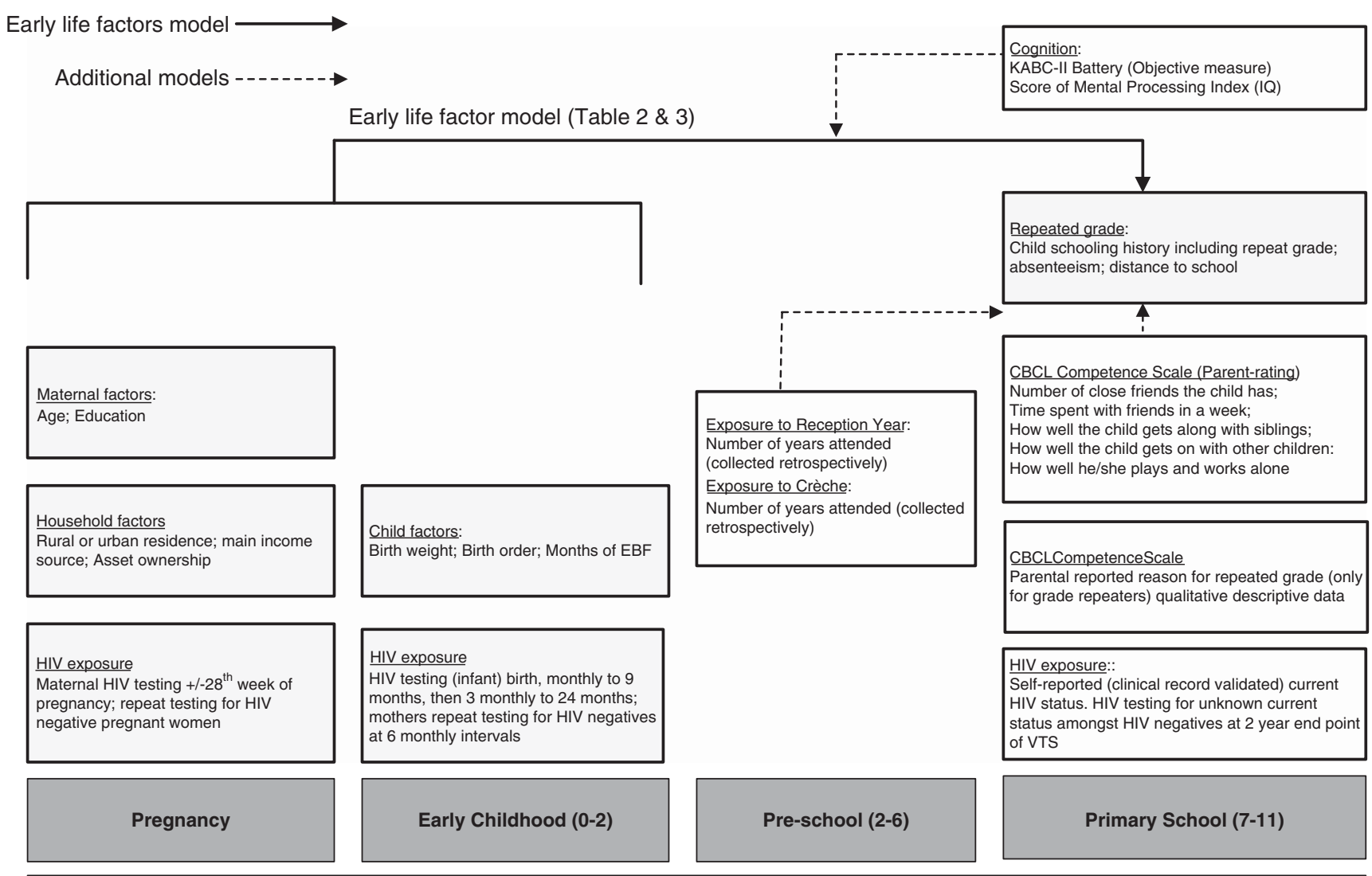

Variables measured across the life-course

Fig. 1. Variables measured across the life course, and how these were used into models predicting repeated grade.

to Grade 3 (foundation phase), Grade 4 to 6 (intermediate phase), Grade 7 to 9 (senior phase) and Grade 10 to 12 (further education and training phase). Compulsory schooling extends from Grade one through to the end of the senior phase (expected age of 15 years). Each child in this analysis was classified as having repeated a school grade or not; repeating Grade R was not included as some children spend more than one year in Grade $\mathrm{R}$ if they start school very young.

\section{Exclusive Breastfeeding}

Standard World Health Organization definitions of exclusive breastfeeding were used, ${ }^{36}$ that is the child received breastmilk only and no other fluids or solids. Days of EBF in the first 6 months were counted, and divided into months of EBF.

\section{Statistical analyses}

Statistical analyses were conducted using Stata version 13, ${ }^{37}$ based on data extracted on 30 October 2014.

\section{Early life factors model}

We first estimated a logistic regression of repeated grade (adjusted for children with the same mother, i.e. twins) on early life covariates, including: maternal age, maternal education, type of residence, main income provider, fridge ownership, child's age, child sex, birth order, birth weight, months of EBF and HIV exposure (mother negative/positive in pregnancy/positive since pregnancy). We were able to include maternal seroconversion since pregnancy as we had data on maternal HIV status during pregnancy from the VTS and her current HIV status in the Saving Brains cohort. Given the significance of child sex in the full model, we repeated the logistic regression stratified by sex.

\section{Additional models}

Given the relevance in the literature of current life variables in children's repeated grade, we also tested the robustness of our findings to mediation by the child's current cognition (which included quartiles of the sum of scaled scores for the MPI). Since we found a significant difference in children who repeated grades based on current sibling relationships, and given this is supported by the literature, ${ }^{13}$ we also tested the parent/caregiver reported quality of the sibling relationship (whether the child was reported to get along well with their siblings) in the mediation model.

Since preparation for school through participation in ECD services is known to increase school readiness and subsequent 
success at school, a separate model examining whether exposure to crèche and/or to reception year were associated with grade repetition was conducted.

\section{Content analysis}

For the children who had repeated a grade, content analysis was used to analyze parent responses to the question on the Competence Scale of the CBCL of why the child had repeated a grade. The analysis involved reading through the 894 responses several times to identify commonly reported reasons for repeated grade in the free text of parent answers. These formed a codebook of reasons for repeat grade, which were used to identify common categories. These patterns were clearly distinguished by key words that the parent used for example 'immature' 'not ready' or 'absenteeism' and were mutually exclusive, and grouped into theoretically similar concepts. Once all the data had been coded, categories were reviewed together with the second (a psychologist) and last author (a paediatrician) and consensus was reached whereby all responses were coded and categories were precisely defined. ${ }^{38}$ These categories were then disaggregated by sex and HIV exposure. Given the small cell counts, children who were exposed to HIV in fetal life, and those whose mothers had become HIV infected post pregnancy, were grouped into one HIV exposed group for the purposes of this analysis.

\section{Results \\ Sample}

A total of 906 children from the original VTS completed follow-up in the Saving Brains cohort. For this analysis, we excluded children who had enrolled in grade one for the first time $(n=6)$, as they had not had the opportunity to repeat a grade, and children with missing schooling data $(n=6)$. A final sample of 894 children was included in the analysis.

\section{Rates of repeated grade}

Of the 894 children $385(43.1 \%)$ had repeated a grade of whom $242(62.9 \%)$ were boys. Table 1 illustrates sample characteristics by repeated grade.

We found significant group differences between children who had repeated a grade and those who had not (see Table 1). Larger proportions of children who had repeated a grade had a mother with HIV and less education (none or primary school only), compared to those who had not repeated a grade. Group differences on the questions on the Competence Scale revealed only one significant difference; that children who repeated grades were also more frequently reported by caregivers to not get along with their siblings $(P=0.022)$.

\section{Early life factors}

The results of the logistic regression model examining early life factors among all children are shown in Table 2. Maternal
Table 1. Descriptive statistics of children and mothers by repeated grade $(\mathrm{n}=894)$

\begin{tabular}{|c|c|c|c|}
\hline & $\begin{array}{c}\text { No repeated } \\
\text { grade }(n=509) \\
{[n(\%)]} \\
\end{array}$ & $\begin{array}{c}\text { Repeated grade } \\
(n=385) \\
{[n(\%)]} \\
\end{array}$ & $P$-value \\
\hline \multicolumn{4}{|l|}{ Maternal factors } \\
\hline Maternal age at birth & & & 0.648 \\
\hline Less than 20 & $102(20.0)$ & $82(21.3)$ & \\
\hline $20-29$ & $243(47.7)$ & $190(49.4)$ & \\
\hline $30+$ & $164(32.2)$ & $113(29.4)$ & \\
\hline Maternal education at birth & & & 0.004 \\
\hline None & $39(7.7)$ & $27(7.0)$ & \\
\hline Primary & $173(34.0)$ & $174(45.2)$ & \\
\hline Grade 10 & $187(36.7)$ & $127(33.0)$ & \\
\hline Grade $12^{\mathrm{a}}$ & $110(21.6)$ & $57(14.8)$ & \\
\hline \multicolumn{4}{|l|}{ Household factors } \\
\hline Residence at birth & & & 0.874 \\
\hline Rural & $312(61.3)$ & $238(61.8)$ & \\
\hline Urban & $197(38.7)$ & $147(38.2)$ & \\
\hline Main income at birth & & & 0.782 \\
\hline Other & $463(91.1)$ & $352(91.7)$ & \\
\hline Mother & $45(8.9)$ & $32(8.3)$ & \\
\hline Missing & 1 & 1 & \\
\hline Owned fridge at birth & & & 0.057 \\
\hline No & $284(55.9)$ & $239(62.2)$ & \\
\hline Yes & $224(44.1)$ & $145(37.8)$ & \\
\hline Missing & 1 & 1 & \\
\hline \multicolumn{4}{|l|}{ Child factors } \\
\hline Child sex & & & $<0.001$ \\
\hline Female & $312(61.3)$ & $143(37.1)$ & \\
\hline Male & $197(38.7)$ & $242(62.9)$ & \\
\hline Child age (years) & & & 0.216 \\
\hline 8 & $23(4.5)$ & $19(4.9)$ & \\
\hline 9 & $237(46.6)$ & $159(41.3)$ & \\
\hline 10 & $211(41.5)$ & $165(42.9)$ & \\
\hline 11 & $38(7.5)$ & $42(10.9)$ & \\
\hline Birth order & & & 0.247 \\
\hline $1-2$ & $284(55.8)$ & $232(60.3)$ & \\
\hline $3-4$ & $119(23.4)$ & $89(23.1)$ & \\
\hline $5+$ & $106(20.8)$ & $64(16.6)$ & \\
\hline Birth weight & & & 0.171 \\
\hline$<2.5 \mathrm{~kg}$ & $44(9.1)$ & $43(11.9)$ & \\
\hline$\geqslant 2.5 \mathrm{~kg}$ & $442(90.9)$ & $317(88.1)$ & \\
\hline Missing & 23 & 25 & \\
\hline EBF (months) ${ }^{\mathrm{b}}$ & & & 0.217 \\
\hline $0-1$ & $54(10.6)$ & $54(14.0)$ & \\
\hline $2-5$ & $149(29.3)$ & $118(30.6)$ & \\
\hline 6 & $305(60.0)$ & $213(55.3)$ & \\
\hline Missing & 1 & 0 & \\
\hline Exposure to HIV & & & 0.053 \\
\hline None & $245(48.2)$ & $155(40.4)$ & \\
\hline Exposure in fetal life & $171(33.7)$ & $155(40.4)$ & \\
\hline Exposure in early & $92(18.1)$ & $74(19.3)$ & \\
\hline \multicolumn{4}{|l|}{ childhood } \\
\hline Missing & 1 & 1 & \\
\hline
\end{tabular}

Bold values are significant at $P<0.05$. EBF, exclusively breastfeed. ${ }^{a}$ Defined as number of days (not cumulative) when child received only breast milk and no other fluids or solids, divided into months.

${ }^{\mathrm{b}}$ In South Africa, grade 12 is the final year of high school.

education at grade 12 relative to no formal education, and birth order of $5+$ relative to $1-2$, were significantly associated with reduced odds of repeated grade in the adjusted model. In the multivariable analyses allowing for a number of other variables (Table 2), boys were three times more likely than girls to repeat a grade (aOR 2.99; 95\% CI 2.22-4.01). 
Table 2. Factors associated with grade repetition $(\mathrm{n}=842)$

\begin{tabular}{|c|c|c|}
\hline & Odds ratio $[\mathrm{CI}] P$-value & Adjusted odds ratio $[\mathrm{CI}] P$-value \\
\hline \multicolumn{3}{|l|}{ Maternal factors } \\
\hline \multicolumn{3}{|l|}{ Maternal age at birth } \\
\hline Less than 20 & $1[1.0-1.0]$ & $1[1.0-1.0]$ \\
\hline $20-29$ & $0.99[0.75-1.30] P=0.931$ & $1.12[0.73-1.71] P=0.613$ \\
\hline $30+$ & $0.98[0.73-1.31] P=0.894$ & $1.22[0.66-2.27] P=0.525$ \\
\hline \multicolumn{3}{|l|}{ Maternal education at birth } \\
\hline None & $1[1.0-1.0]$ & $1[1.0-1.0]$ \\
\hline Primary & $1.36[0.80-2.30] P=0.251$ & $1.11[0.58-2.11] P=0.752$ \\
\hline Grade 10 & $0.89[0.53-1.52] P=0.673$ & $0.63[0.32-1.23] P=0.173$ \\
\hline Grade 12 & $0.69[0.39-1.22] P=0.197$ & $0.44[0.21-0.90] P=0.024$ \\
\hline \multicolumn{3}{|l|}{ Household factors } \\
\hline \multicolumn{3}{|l|}{ Residence at birth } \\
\hline Rural & $1[1.0-1.0]$ & $1[1.0-1.0]$ \\
\hline Urban & $0.95[0.73-1.25] P=0.731$ & $0.96[0.69-1.32] P=0.785$ \\
\hline \multicolumn{3}{|l|}{ Main income at birth } \\
\hline Other & $1[1.0-1.0]$ & $1[1.0-1.0]$ \\
\hline Mother & $0.97[0.60-1.56] P=0.906$ & $0.90[0.51-1.57] P=0.7$ \\
\hline \multicolumn{3}{|l|}{ Owned a fridge at birth } \\
\hline No & $1[1.0-1.0]$ & $1[1.0-1.0]$ \\
\hline Yes & $0.77[0.59-1.01] P=0.062$ & $0.82[0.60-1.12] P=0.208$ \\
\hline \multicolumn{3}{|l|}{ Child factors } \\
\hline \multicolumn{3}{|l|}{ Child age (years) } \\
\hline 8 & $1[1.0-1.0]$ & $1[1.0-1.0]$ \\
\hline 9 & $1.07[0.76-1.50] P=0.692$ & $0.83[0.39-0.75] P=0.622$ \\
\hline 10 & $1.09[0.77-1.53] P=0.637$ & $0.97[0.46-2.07] P=0.94$ \\
\hline 11 & $1.77[1.15-2.73] P=0.01$ & $1.19[0.51-2.81] P=0.69$ \\
\hline \multicolumn{3}{|l|}{ Child sex } \\
\hline Female & $1[1.0-1.0]$ & $1[1.0-1.0]$ \\
\hline Male & $2.04[1.66-2.50] P<0.001$ & $2.99[2.22-4.01] P<0.001$ \\
\hline \multicolumn{3}{|l|}{ Birth order } \\
\hline $1-2$ & $1[1.0-1.0]$ & $1[1.0-1.0]$ \\
\hline $3-4$ & $1.03[0.81-1.31] P=0.814$ & $0.74[0.48-1.14] P=0.175$ \\
\hline $5+$ & $1.03[0.80-1.34] P=0.819$ & $0.46[0.25-0.86] P=0.015$ \\
\hline \multicolumn{3}{|l|}{ Birth weight } \\
\hline$<2.5 \mathrm{~kg}$ & $1[1.0-1.0]$ & $1[1.0-1.0]$ \\
\hline$\geqslant 2.5 \mathrm{~kg}$ & $0.71[0.45-1.13] P=0.15$ & $0.71[0.44-1.16] P=0.175$ \\
\hline \multicolumn{3}{|l|}{$\operatorname{EBF}\left(\right.$ months) ${ }^{\mathrm{a}}$} \\
\hline 0-1 month & $1[1.0-1.0]$ & $1[1.0-1.0]$ \\
\hline $2-5$ months & $0.77[0.49-1.22] P=0.267$ & $0.76[0.45-1.28] P=0.298$ \\
\hline 6 months & $0.70[0.46-1.07] P=0.102$ & $0.64[0.39-1.06] P=0.083$ \\
\hline \multicolumn{3}{|l|}{ Exposure to HIV } \\
\hline None & $1[1.0-1.0]$ & $1[1.0-1.0]$ \\
\hline Exposure in fetal life & $1.45[1.08-1.95] P=0.013$ & $1.26[0.88-1.80] P=0.207$ \\
\hline Exposure in early childhood & $1.26[0.88-1.82] P=0.209$ & $1.06[0.71-1.61] P=0.766$ \\
\hline
\end{tabular}

EBF, exclusively breastfeed.

Bolded results are significant $(P<0.05)$ and italicized results are trends, defined by $P>0.05$ and $P<0.09$.

${ }^{a}$ Defined as number of days (not cumulative) when child received only breast milk and no other fluids or solids, divided into months.

Given the strong associations between child sex and repeated grade, we next tested the model stratified by sex (Table 3). Girls whose mothers had completed grade 12 were less likely to have repeated a grade than those whose mothers had no education (aOR $0.33 ; 95 \%$ CI 0.1-0.9). Girls whose mothers were
HIV-positive in pregnancy had double the odds of repeating a grade than those whose mothers were HIV-negative $(\mathrm{aOR}$ 2.17; 95\% CI 1.3-3.8). However relevant variables were different for boys: ownership of a fridge compared to nonownership and exposure to breastfeeding for 6-months relative 


\begin{tabular}{|c|c|c|c|c|}
\hline & \multicolumn{2}{|c|}{ Girls $(n=429)$} & \multicolumn{2}{|c|}{ Boys $(n=413)$} \\
\hline & Odds ratio $[\mathrm{CI}] P$-value & Adjusted odds ratio $[\mathrm{CI}] P$-value & Odds ratio $[\mathrm{CI}] P$-value & Adjusted odds ratio $[\mathrm{CI}] P$-value \\
\hline \multicolumn{5}{|l|}{ Maternal factors } \\
\hline \multicolumn{5}{|l|}{ Maternal age at birth } \\
\hline Less than 20 & $1[1.0-1.0]$ & $1[1.0-1.0]$ & $1[1.0-1.0]$ & $1[1.0-1.0]$ \\
\hline $20-29$ & $0.81[0.47-1.38] P=0.432$ & $1.02[0.56-1.87] P=0.945$ & $1.17[0.69-2.0] P=0.556$ & $1.32[0.71-2.45] P=0.389$ \\
\hline $30+$ & $0.792[0.438-1.431] P=0.439$ & $1.18[0.49-2.82] P=0.711$ & $0.94[0.53-1.65] P=0.819$ & $1.53[0.61-3.84] P=0.368$ \\
\hline \multicolumn{5}{|l|}{ Maternal education at birth } \\
\hline None & $1[1.0-1.0]$ & $1[1.0-1.0]$ & $1[1.0-1.0]$ & $1[1.0-1.0]$ \\
\hline Primary & $1.28[0.58-2.84] P=0.549$ & $1.32[0.57-3.08] P=0.518$ & $1.38[0.57-3.30] P=0.476$ & $0.93[0.33-2.59] P=0.890$ \\
\hline Grade 10 & $0.71[0.32-1.59] P=0.406$ & $0.51[0.21-1.22] P=0.128$ & $1.13[0.46-2.74] P=0.792$ & $0.78[0.27-2.30] P=0.655$ \\
\hline Grade 12 & $0.52[0.22-1.28] P=0.152$ & $0.33[0.12-0.88] P=0.027$ & $0.79[0.32-2.00] P=0.626$ & $0.48[0.15-1.50] P=0.204$ \\
\hline \multicolumn{5}{|l|}{ Household factors } \\
\hline \multicolumn{5}{|l|}{ Residence at birth } \\
\hline Rural & $1[1.0-1.0]$ & $1[1.0-1.0]$ & $1[1.0-1.0]$ & $1[1.0-1.0]$ \\
\hline Urban & $0.76[0.49-1.18] P=0.223$ & $0.73[0.45-1.20] P=0.215$ & $1.04[0.70-1.55] P=0.838$ & $1.20[0.76-1.88] P=0.442$ \\
\hline \multicolumn{5}{|l|}{ Main income at birth } \\
\hline Other & $1[1.0-1.0]$ & $1[1.0-1.0]$ & $1[1.0-1.0]$ & $1[1.0-1.0]$ \\
\hline Mother & $1.22[0.57-2.65] P=0.609$ & $1.03[0.41-2.55] P=0.957$ & $0.79[0.41-1.55] P=0.497$ & $0.72[0.35-1.51] P=0.389$ \\
\hline \multicolumn{5}{|l|}{ Owned fridge at birth } \\
\hline No & $1[1.0-1.0]$ & $1[1.0-1.0]$ & $1[1.0-1.0]$ & $1[1.0-1.0]$ \\
\hline Yes & $0.82[0.54-1.25] P=0.36$ & $0.88[0.55-1.40] P=0.579$ & $0.70[0.47-1.04] P=0.076$ & $0.66[0.43-1.02] P=0.063$ \\
\hline \multicolumn{5}{|l|}{ Child factors } \\
\hline \multicolumn{5}{|l|}{ Child age (years) } \\
\hline 8 & $1[1.0-1.0]$ & $1[1.0-1.0]$ & $1[1.0-1.00]$ & $1[1.0-1.0]$ \\
\hline 9 & $1.03[0.41-2.60] P=0.95$ & $0.95[0.33-2.71] P=0.924$ & $0.66[0.22-1.97] P=0.454$ & $0.73[0.24-2.18] P=0.568$ \\
\hline 10 & $0.91[0.36-2.30] P=0.835$ & $0.70[0.24-2.03] P=0.515$ & $1.05[0.35-3.15] P=0.936$ & $1.21[0.41-3.64] P=0.728$ \\
\hline 11 & $0.53[0.165-1.707] P=0.288$ & $0.32[0.09-1.18] P=0.086$ & $3.63[0.91-14.42] P=0.068$ & $4.99[1.23-20.31] P=0.025$ \\
\hline \multicolumn{5}{|l|}{ Birth order } \\
\hline $1-2$ & $1[1.0-1.0]$ & $1[1.0-1.0]$ & $1[1.0-1.0]$ & $1[1.0-1.0]$ \\
\hline $3-4$ & $0.76[0.45-1.28] P=0.304$ & $0.53[0.27-1.02] P=0.055$ & $1.16[0.72-1.87] P=0.542$ & $0.98[0.52-1.83] P=0.942$ \\
\hline $5+$ & $0.76[0.43,1.35] P=0.345$ & $0.41[0.16-1.02] P=0.055$ & $0.71[0.42-1.20] P=0.199$ & $0.42[0.17-1.06] P=0.066$ \\
\hline \multicolumn{5}{|l|}{ Birth weight } \\
\hline$<2.5 \mathrm{~kg}$ & $1[1.0-1.0]$ & $1[1.0-1.0]$ & $1[1.0-1.0]$ & $1[1.0-1.0]$ \\
\hline \multirow{2}{*}{\multicolumn{5}{|c|}{$\begin{array}{c}\text { NEF (months) } \\
\mathrm{EBF}\end{array}$}} \\
\hline & & & & \\
\hline $0-1$ month & $1[1.0-1.0]$ & $1[1.0-1.0]$ & $1[1.0-1.0]$ & $1[1.000,1.000]$ \\
\hline $2-5$ months & $0.90[0.44-1.82] P=0.766$ & $0.98[0.43-2.25] P=0.966$ & $0.76[0.39-1.48] P=0.421$ & $0.67[0.33-1.36] P=0.261$ \\
\hline 6 months & $0.75[0.39-1.44] P=0.383$ & $0.76[0.33-1.74] P=0.522$ & $0.72[0.39-1.32] P=0.286$ & $0.56[0.29-1.10] P=0.091$ \\
\hline \multicolumn{5}{|l|}{ Exposure to HIV } \\
\hline None & $1[1.0-1.0]$ & $1[1.0-1.0]$ & $1[1.0-1.0]$ & $1[1.0-1.0]$ \\
\hline Exposure in fetal life & $1.69[1.06-2.71] P=0.028$ & $2.17[1.26-3.75] P=\mathbf{0 . 0 0 5}$ & $1.34[0.86-2.08] P=0.198$ & $0.85[0.51-1.40] P=0.515$ \\
\hline Exposure in early childhood & $1.67[0.94-2.99] P=0.082$ & $1.48[0.78-2.79] P=0.230$ & $0.96[0.57-1.64] P=0.891$ & $0.83[0.47-1.47] P=0.525$ \\
\hline
\end{tabular}

EBF, exclusively breastfeed.

Bolded results are significant $(P<0.05)$ and italicized results are trends, defined by $P>0.05$ and $P<0.09$.

${ }^{a}$ Defined as number of days (not cumulative) when child received only breast milk and no other fluids or solids, divided into months. 
to less than 1 month showed a trend towards reducing the odds of repeating a grade. Maternal HIV status was not associated with grade repetition in boys.

Table 3 shows that there was a trend for both boys and girls being higher in birth order (having at least some older siblings) to have reduced odds of repeated grade, but this was only of borderline significance.

\section{Additional models}

We next tested the effects of including the child's MPI score and parent/caregiver report of quality of sibling relationship in the sex-stratified models. For girls, the effect of maternal education (Grade 12) on repeated grade was no longer significant (aOR 0.56; 95\% CI 0.2-1.7), most likely due to the well-established strong association between maternal education and child cognition. Most other effects remained consistent: the birth order trend for girls 3rd to 4th or 5th and more and for boys who were 5 th or more remained. The effect of HIV exposure in pregnancy for girls remained significant (aOR 2.1; 95\% CI 1.7-3.8) and for boys, the effect of fridge ownership became significant (aOR 0.59; 95\% CI 0.4-1.0).

Overall, most children started school aged seven or older, just under half of the children attended at least one year of crèche (429/894) and the majority completed at least one reception year (770/894) before entry into first grade. Exposure to crèche $(\mathrm{aOR}=0.88 ; 95 \% \mathrm{CI} 0.7-1.2)$ and reception year $(\mathrm{aOR}=0.78 ; 95 \% \mathrm{CI} 0.5-1.1)$ showed a trend of reducing odds of grade repetition, but were not significant.

\section{Content analysis}

Caregiver responses from the question on the Competence Scale regarding the reasons why the parent/caregiver thought the child had repeated grades were grouped into six main categories with several corresponding subcategories.

Overall, a third of children were categorized as having experienced issues with school readiness. This category was defined by caregivers describing their children as being too playful and emotionally immature and unable to self-regulate sufficiently to be successful at school. These descriptions were interpreted as referring to social and emotional development. The next most common reason for failure was children who had experienced difficulty with specific aspects of schooling or subjects, with caregivers reporting that children had difficulty with literacy and with first language isiZulu. Thirdly, a proportion of parent responses alluded to their child experiencing learning difficulties. This category was made up of responses where parents specifically reported problems with not coping, concentration difficulties and being concerned that their child may potentially have a learning difficulty or disability. A smaller, but still substantial group of children were reported to be poorly motivated to attend school, including truancy and other behavioural problems.

These categories and subcategories can be seen in Table 4 where they were further disaggregated by sex and HIV. $Z$ tests for proportions showed that most of these differences were not significant, however for boys there was a significant difference in disrupted schooling by HIV exposure (HIV unexposed $3.8 \% v$. HIV exposed; $12.4 \% \mathrm{Z}=-2.36 P=0.018$ ).

\section{Discussion}

Our study showed a high rate (43\%) of grade repetition among children in the early years of school (aged 7-11 years), almost double previous estimates from studies elsewhere in South Africa $^{39,40}$ and higher than a recent estimate (25.8\%) among 15 year olds in the Birth to Twenty Cohort (BT20). ${ }^{41}$ Similar to literature in South Africa, and internationally, ${ }^{24,42}$ boys were three times more likely to repeat a grade than girls, after adjusting for other variables associated with grade repetition.

When examining the characteristics of children who repeated a grade we see that, as has been shown in the United States and rural South Africa, ${ }^{10,43}$ higher numbers of children whose mothers had a lower education level repeated a grade. Importantly, higher numbers of HIV exposed children had repeated a grade than non-exposed children. Many studies in Africa ${ }^{18,44}$ have suggested that HIV-related orphanhood is associated with poor educational outcomes, including repeated grade. ${ }^{45,46} \mathrm{In}$ this study, we focused on children whose mothers were still alive, with our results suggesting that grade repetition and problems with failures in school begin earlier, and may even precede maternal illness or death.

We also found that good sibling relationships were more common among non-repeaters. While some literature has shown that a larger family size may be detrimental to educational outcomes for children, ${ }^{47}$ the potential influence of a good sibling relationship to mediate these effects has been largely unexamined. Some recent literature has suggested that older siblings positively influence the cognitive development of younger siblings. ${ }^{13}$ It is plausible that children who have good sibling relationships might have better social skills more generally, and as a consequence may have better access to support for schooling, and better relationships with teachers. ${ }^{48}$ However if this was the case, one might have expected to see significant differences with regards to other social relationships, such as those with peers. Meanwhile, in this study, the differences seem to be sibling-specific. The significance of increased birth order reducing the likelihood of grade repetition and the finding that fewer children who got along well with their siblings had repeated a grade, might suggest some potential for older siblings to play a protective role in educational outcomes in this context. In HICs, a higher birth order has been shown to result in poor educational outcomes as parents invest fewer resources in each child as the family grows. ${ }^{47,49}$ However, the inverse of this hypothesis has been found in LMICs with children and adolescents. ${ }^{50-52}$ In South Africa, researchers have argued that older siblings often contribute financially to younger siblings' education, ${ }^{52}$ and may be closely involved with younger siblings' daily lives, in particular since it is culturally normative to take on increased responsibilities 
Table 4. Mother/caregiver report on reasons the child repeated a grade, disaggregated by HIV exposure and child sex $(\mathrm{n}=384)$

\begin{tabular}{|c|c|c|c|c|c|c|c|c|}
\hline & \multicolumn{4}{|c|}{ Girls $(n=142)$} & \multicolumn{4}{|c|}{ Boys $(n=242)$} \\
\hline & Negative $(n=50)$ & Positive $(n=92)$ & Total & $\mathrm{Z}(P)$ & Negative $(n=105)$ & Positive $(n=137)$ & Total & $\mathrm{Z}(P)$ \\
\hline School readiness issues (\%) & $18(36.0)$ & $22(23.9)$ & $40(28.2)$ & $Z=1.53 P=0.126$ & $41(39.1)$ & $44(32.1)$ & $85(35.1)$ & $\mathrm{Z}=1.12 P=0.263$ \\
\hline Playful (\%) & $9(18.0)$ & $8(8.7)$ & $17(12.0)$ & - & $28(26.7)$ & $26(19.0)$ & $54(22.3)$ & - \\
\hline Immaturity (\%) & $7(14.0)$ & $14(15.2)$ & $21(14.8)$ & - & $11(10.5)$ & $13(9.5)$ & $24(9.9)$ & - \\
\hline Shy/emotional (\%) & $2(4.0)$ & $0(0.0)$ & $2(1.4)$ & - & $2(1.9)$ & $5(3.7)$ & $7(2.9)$ & - \\
\hline Specific area/subject difficulty (\%) & $9(18.0)$ & $15(16.3)$ & $24(16.9)$ & $Z=0.26 P=0.795$ & $19(18.1)$ & $30(21.9)$ & $49(20.3)$ & $Z=-0.73 P=0.465$ \\
\hline First language isiZulu (\%) & $5(10.0)$ & $5(5.4)$ & $10(7.0)$ & - & $4(3.8)$ & $12(8.8)$ & $16(6.6)$ & - \\
\hline Second language English (\%) & $0(0.0)$ & $4(4.3)$ & $4(2.8)$ & - & $0(0.0)$ & $0(0.0)$ & $0(0.0)$ & - \\
\hline Numeracy/maths (\%) & $0(0.0)$ & $1(1.1)$ & $1(0.7)$ & - & $1(1.0)$ & $3(2.2)$ & $4(1.7)$ & - \\
\hline Other subjects $(\%)$ & $0(0.0)$ & $1(1.1)$ & $1(0.7)$ & - & $1(1.0)$ & $2(1.5)$ & $3(1.2)$ & - \\
\hline Literacy $(\%)$ & $4(8.0)$ & $3(3.3)$ & $7(4.9)$ & - & $12(11.4)$ & $12(8.8)$ & $24(9.9)$ & - \\
\hline Teacher problems (\%) & $0(0.0)$ & $1(1.1)$ & $1(0.7)$ & - & $1(1.0)$ & $1(0.7)$ & $2(0.8)$ & - \\
\hline Learning difficulties (\%) & $9(18.0)$ & $23(25.0)$ & $32(22.5)$ & $Z=-0.954 P=0.342$ & $19(18.1)$ & $20(14.6)$ & $39(16.1)$ & $\mathrm{Z}=0.733 P=0.465$ \\
\hline Overall not coping (\%) & $5(10.0)$ & $5(5.4)$ & $10(7.0)$ & - & $4(3.8)$ & $5(3.6)$ & $9(3.7)$ & - \\
\hline Concentration $(\%)$ & $3(6.0)$ & $6(6.5)$ & $9(6.3)$ & - & $5(4.8)$ & $4(2.9)$ & $9(3.7)$ & - \\
\hline Potential disability (\%) & $1(2.0)$ & $3(3.3)$ & $4(2.8)$ & - & $4(3.8)$ & $5(3.6)$ & $9(3.7)$ & - \\
\hline Known disability (\%) & $0(0.0)$ & $3(3.3)$ & $3(2.1)$ & - & $3(2.9)$ & $2(1.5)$ & $5(2.1)$ & - \\
\hline Poor comprehension (\%) & $0(0.0)$ & $5(5.4)$ & $5(3.5)$ & - & $2(1.9)$ & $3(2.2)$ & $5(2.1)$ & - \\
\hline Limited learning support (\%) & $0(0.0)$ & $1(1.1)$ & $1(0.7)$ & - & $1(1.0)$ & $1(0.7)$ & $2(0.8)$ & - \\
\hline Motivation Problems (\%) & $4(8.0)$ & $10(10.9)$ & $14(9.9)$ & $Z=-0.548 P=0.582$ & $14(13.3)$ & $15(10.9)$ & $29(12.0)$ & $\mathrm{Z}=0.566 P=0.569$ \\
\hline Not focused (\%) & $2(4.0)$ & $4(4.3)$ & $6(4.2)$ & - & $7(6.7)$ & $4(2.9)$ & $11(4.6)$ & - \\
\hline Truancy (\%) & $1(2.0)$ & $2(2.2)$ & $3(2.1)$ & - & $4(3.8)$ & $4(2.9)$ & $8(3.3)$ & - \\
\hline Homework (\%) & $1(2.0)$ & $0(0.0)$ & $1(0.7)$ & - & $3(2.9)$ & $4(2.9)$ & $7(2.9)$ & - \\
\hline Behavioural (\%) & $0(0.0)$ & $3(3.3)$ & $3(2.1)$ & - & $0(0.0)$ & $1(0.7)$ & $1(0.4)$ & - \\
\hline Doesn't like school (\%) & $0(0.0)$ & $1(1.1)$ & $1(0.7)$ & - & $0(0.0)$ & $2(1.5)$ & $2(0.8)$ & - \\
\hline Disrupted Schooling (\%) & $4(8.0)$ & $9(9.8)$ & $13(9.2)$ & $Z=-0.352 P=0.726$ & $4(3.8)$ & $17(12.4)$ & $21(8.7)$ & $\mathrm{Z}=-2.36 P=\mathbf{0 . 0 1 8}$ \\
\hline Attendance (\%) & $0(0.0)$ & $6(6.5)$ & $6(4.2)$ & - & $3(2.9)$ & $12(8.8)$ & $15(6.2)$ & - \\
\hline Relocation (\%) & $4(8.0)$ & $2(2.2)$ & $6(4.2)$ & - & $1(1.0)$ & $2(1.5)$ & $3(1.2)$ & - \\
\hline Missed exams (\%) & $0(0.0)$ & $1(1.1)$ & $1(0.7)$ & - & $0(0.0)$ & $3(2.2)$ & $3(1.2)$ & - \\
\hline Health $(\%)$ & $3(6.0)$ & $5(5.4)$ & $8(5.6)$ & $Z=0.14 P=0.889$ & $3(2.9)$ & $4(2.9)$ & $7(2.9)$ & $\mathrm{Z}=-0.03 P=0.976$ \\
\hline Child medical problem (\%) & $2(4.0)$ & $2(2.2)$ & $4(2.8)$ & - & $3(2.9)$ & $3(2.2)$ & $6(2.5)$ & - \\
\hline Trauma $(\%)$ & $1(2.0)$ & $3(3.3)$ & $4(2.8)$ & - & $0(0.0)$ & $1(0.7)$ & $1(0.4)$ & - \\
\hline Maternal illness (\%) & $0(0.0)$ & $0(0.0)$ & $0(0.0)$ & - & $0(0.0)$ & $1(0.7)$ & $1(0.4)$ & - \\
\hline Don't Know (\%) & $2(4.0)$ & $3(3.3)$ & $5(3.5)$ & - & $3(2.9)$ & $4(2.9)$ & $7(2.9)$ & - \\
\hline Missing (\%) & $1(2.0)$ & $5(5.4)$ & $6(4.2)$ & - & $2(1.9)$ & $3(2.2)$ & $5(2.1)$ & - \\
\hline
\end{tabular}


towards younger siblings. ${ }^{53}$ Older siblings who have a good relationship with younger siblings might be more likely to be involved with supporting and facilitating learning, which may be particularly important in South Africa where, given historical disadvantages, siblings are likely to have received a higher level and quality of education than their mothers. ${ }^{54}$ This might point to opportunities for family interventions to support older siblings in the care of younger siblings in the household. Further research is needed to understand the nature of sibling relationships in large, extended, rural households.

When we examined the early life factors, stratified by sex, we found maternal education to reduce odds of grade repetition for girls, but not boys. The influence of maternal education for girls only was also found in a study from Guinea in Western Africa. ${ }^{55}$ In Western Africa the authors proposed that this disparity by sex could be attributed to maternal household power, particularly in patriarchal societies where schooling access is low. For instance, if a mother has a higher level of education she may have increased decision-making power in the household and direct resources towards her daughter's education, even though the culture may favour the boy child. ${ }^{55}$ A limitation of the current study is that we did not measure father's education. Previous research from the Africa Centre setting ${ }^{44}$ showed some selective sex effects following orphanhood, whereby maternal outcomes were more strongly associated with girl children's outcomes and paternal outcomes more associated with boys' outcomes.

Maternal HIV in fetal life was associated with an increased risk of repeating grade for all children, with the strongest effect for girls. While the existing literature has shown HIV-exposed girls to be more vulnerable to poor educational outcomes, ${ }^{15}$ this study shows the effect to be stronger when the girl is exposed to HIV from fetal life, as opposed to during childhood. We expect that this may be a result of the effects of the mother's longer exposure to infection, which may have led to ill health and reduced caregiving capacity over time. This is consistent with literature that supports the hypothesis that maternal HIV impacts on children's education indirectly through the caregiver. ${ }^{57}$

Regarding impact on girls, previous studies have hypothesized that the girl child's vulnerability is linked to the mother's illness which in turn leads to increased domestic responsibilities, chores and care giving activities when their mothers are ill. $^{58,59}$ This in turn is associated with a drop in school attendance. ${ }^{44}$ However evidence from parent report in our study does not corroborate either maternal illness or disrupted schooling as primary reasons for repeating grades among girls. Instead, a lack of school readiness and developmental immaturity, along with specific learning problems were more commonly cited as reasons for grade repetition among HIV-exposed girls. Interestingly, HIV-exposed girls were as commonly reported to have motivational problems (including a lack of focus and truancy) as HIV-exposed boys. Research is needed to elucidate the pathways of this effect on girls' education in the early years in order to inform interventions, as it is likely pathways are more complex than the onset of parental illness alone. Understanding these pathways is also made more urgent given that HIV exposure for girls is a predictor of later engagement in HIV-risk behaviour ${ }^{60}$ and additional years in school has been shown to mediate this risk. ${ }^{26}$

When current cognition and the effect of sibling relationships were tested as mediators, socioeconomic status, measured here by fridge ownership, was significantly associated with a reduced likelihood of repeating a grade for boys. While there is evidence that boys living in poverty are more stunted in their physical development than girls in sub-Saharan Africa, ${ }^{61}$ the mechanisms by which poverty affects schooling outcomes for boys particularly, are less clear. Some literature has suggested that the number of hours in a day that a boy attends school in South Africa is particularly vulnerable to variation in permanent income for the household. ${ }^{50}$ It is hypothesized that in these income insecure settings, boys (more than girls) may be more vulnerable to being drawn into child labour or not being able to afford school fees, which in turn might increase disruptions in attendance. ${ }^{62}$ For instance, boys' school attendance in Ethiopia was found to be influenced by partaking in farming activities and generating income for the family. ${ }^{50}$

In the sex stratified model the association between maternal HIV status and repeating a grade did not reach statistical significance for boys. However in the parent reports for boys who did repeat a grade, we see a significantly higher proportion of HIV-exposed boys being reported to have failed as a result of school disruption compared to HIV-unexposed boys. Disrupted schooling included inconsistent attendance, school relocation and missed examinations. This may lend support to the hypothesis that boys' schooling is disrupted by socio-economic factors, and that this is particularly heightened in the presence of maternal HIV. However, it is equally plausible that a mother's HIV status has indirect effects for boys. For example, a mother may have relocated to access HIV treatment, which might have been good for her health, but resulted in school mobility which may have had disruptive effects on her child's education outcomes. In a cross-sectional analysis of the BT20 cohort, school mobility was one of the stronger factors associated with having repeated a grade by age $15,{ }^{41}$ adding support to existing evidence from Africa which shows that HIV-exposed children (including boys) are prone to disrupted schooling.

We found that, among subject specific learning problems, the most common was related to children's first language (IsiZulu). For many South African children, the first two years of schooling may be the first time they learn English (their second language) and it will also be the first time they attempt to read and write in their mother tongue. Challenges with the instruction of young children in isiZulu have been cited in the literature, and while mother-tongue learning is encouraged in KwaZulu-Natal, teachers often opt to focus on English, perceiving it to be the more important language to master for later opportunities. ${ }^{63}$ This may result in inadequate support for language subjects in the early years, yet the child's passing a grade is contingent on them passing their first language subject from as early as first grade. 
A worrisome number of children (11\%) were reported by their parents to have failed due to motivational problems, including truancy. These children may be exhibiting the first signs of becoming disengaged in school which may lead to eventual dropout, ${ }^{64}$ which is concerning given their young age. Estimates of truancy are poorly documented, in particular for younger children, but it has been acknowledged as a problem in South Africa. ${ }^{65}$ A study of truancy among adolescents in Swaziland found rates of $21.6 \%$ (27\% boys; $17 \%$ girls). Being a male, having been bullied, lower school grades, and alcohol use were positively associated with truancy. Home environment has been shown to be an important determinant of truancy, with parental supervision and involvement curbing truancy and promoting motivation among children at school. ${ }^{66-68}$ Motivational problems as a reason for failure were as common among girls as boys in this research.

Lastly, our results also point to the importance of preparation for schooling and subject specific schooling support in the early years of a child's life. When examining other factors commonly reported as reasons for failing grade by the parent, the most common was a lack of school readiness and what parents described as developmental immaturity, followed by subject-specific learning problems and overall learning problems. Children reported to be developmentally immature may not be ready for school, as is commonly reported among children living in poverty. ${ }^{69}$ Interventions focused on improved screening of school readiness could be promoted, as well as early identification of learning disabilities, so the appropriate referral can be made. While children should not enter school before they are ready, later school entry can also have a negative impact on educational attainment. ${ }^{41}$ As such, efforts to improve school readiness through increased quality, or more years of, reception year may be beneficial. However, as illustrated in this research access to reception schooling alone may not be sufficient. Future research could examine the effects of sibling and family support on younger children's schooling, and the advantages this may offer as a potential area of intervention support for particularly vulnerable, including HIV-exposed, children.

The limitations of this study include that we did not collect data on the quality of schooling, and that our data is limited to parental report. Further, we do not include data from children of their understanding of reasons for repeated grade or reports from teachers.

The strengths of this research include its longitudinal design, the inclusion of both HIV-exposed (during pregnancy and post pregnancy) and HIV-unexposed children, the examination of earliest records of failures in school, and an objective measure of children's cognition. Importantly, while we are limited to parental report, we used well validated measures to capture these. To our knowledge this is the only examination of early life factors associated with repeated grade in early primary school in South Africa. We find that HIV exposure has particularly detrimental effects for girls. Although the mechanism of this requires further research, it is likely to reflect social, rather than biological, effects of exposure. While poverty has unfavourable effects for boys, they are also vulnerable to school disruptions, an area requiring further research. Maternal education and support from older siblings along with early school readiness preparation may provide opportunities for intervention. Educational outcome are directly linked to longer term health and human capital outcomes, and early failures are strong predictors of later educational outcomes. Understanding the mechanisms by which children fail in school can inform intervention investments, and further research is needed, in particular to understand the differential gender effects.

\section{Acknowledgements}

The authors are grateful to all women and children enrolled in the study, the field and data management team, in particular Samu Dube. They thank Colin Newell for data management during the study, Kobus Herbst and Dickman Gareta and the research platform management team for support during the analysis. They thank the Community Liaison Office of the Africa Centre and Community Advisory Board for their guidance throughout the study.

Joanie Mitchell contributed to interpretation of data, drafted the manuscript and critically revised the manuscript. Brian Houle contributed to the analysis and interpretation of the data. Tamsen Rochat and Ruth Bland contributed to interpretation of data and critically reviewing the manuscript. Marie-Louise Newell and Alan Stein critically revised the manuscript and contributed to refining the analysis and manuscript. The investigators of the Vertical Transmission Study are acknowledged and include Professor Hoosen Coovadia (PI), Anna Coutsoudis and Nigel Rollins.

\section{Financial Support}

The authors are grateful to Grand Challenges, Canada, who funded this re-enrolment study as part of their 'Saving Brains' initiative (Grand Challenges 0063-03).

\section{Conflicts of Interest}

None.

\section{Ethical Standards}

Ethics permission was granted by the Biomedical Research Ethics Committee (BREC), University of KwaZulu-Natal, South Africa (BF184/12).

\section{References}

1. Walker SP, Wachs TD, Grantham-McGregor S, et al. Inequality in early childhood: risk and protective factors for early child development. Lancet. 2011; 378, 1325-1338.

2. Engle P, Black MM, JR B, et al. Strategies to avoid the loss of developmental potential in more than 200 million children in the developing world. Lancet. 2007; 369, 229-242.

3. Entwistle D, Alexander KL, Olson LS. First grade and educational attainment by age 22: a new story. Am J Sociol. 2005; 110, 1458-1502. 
4. Jimerson SR, Anderson GE, Whipple AD. Winning the battle and losing the war: examining the relation between grade retention and dropping out of high school. Psychol Schools. 2002; 39, 441-457.

5. Gomes-Neto JB, Hanushek EA. Causes and consequences of grade repetition: evidence from Brazil. Econ Dev Cult Change. 1994; 43, 117-148.

6. Freudenberg N, Ruglis J. Reframing school dropout as a public health issue. Prev Chronic Dis. 2007; 4, 107.

7. Oreopoulos P. Do dropouts drop out too soon? Wealth, health and happiness from compulsory schooling. J Public Econ. 2007; 91, 2213-2229.

8. Kamal M, Bener A. Factors contributing to school failure among school children in very fast developing Arabian Society. Oman Med J. 2009; 24, 212.

9. Hamre B, Pianta R. Can instructional and emotional support in the first-grade classroom make a difference for children at risk of school failure? Child Dev. 2005; 76, 949-967.

10. Byrd RS, Weitzman ML. Predictors of early grade retention among children in the United States. Pediatrics. 1994; 93, 481-487.

11. Blair C. The early identification of risk for grade retention among African American children at risk for school difficulty. Appl Dev Sci. 2001; 5, 37-50.

12. Liu J. Childhood externalizing behavior: theory and implications. Child Adolesc Psychiatr Nurs. 2004; 17, 93-103.

13. Dai X, Heckman JJ. Older siblings' contributions to young child's cognitive skills. Econ Model. 2013; 35, 235-248.

14. Development DoS. Guidelines for early childhood development services. South Africa: UNICEF, 2006. Retrieved 24th August 2015 from http://www.unicef.org/southafrica/SAF_resources_ecdguidlines. pdf

15. Guo Y, Li X, Sherr L. The impact of HIV/AIDS on children's educational outcome: a critical review of global literature. AIDS Care. 2012; 24, 993-1012.

16. Birdthistle I, Floyd S, Nyagadza A, et al. Is education the link between orphanhood and HIV/HSV-2 risk among female adolescents in urban Zimbabwe? Soc Sci Med. 2009; 68, 1810-1818.

17. Rescorla L, Achenbach T, Ivanova MY, et al. Behavioral and emotional problems reported by parents of children ages 6 to 16 in 31 societies. J Emot Behav Disord. 2007; 15, 130-142.

18. Ainsworth M, Beegle K, Koda G. The impact of adult mortality and parental deaths on primary schooling in North-Western Tanzania. J Dev Stud. 2005; 41, 412-439.

19. Bhargava A. AIDS epidemic and the psychological well-being and school participation of Ethiopian orphans. Psychol Health Med. 2005; 10, 263-275.

20. Yamano T, Jayne TS. Working-age adult mortality and primary school attendance in rural Kenya. Econ Dev Cult Change. 2005; 53, 619-653.

21. Ainsworth M, Filmer D. Inequalities in children's schooling: AIDS, orphanhood, poverty, and gender. World Dev. 2006; 34, 1099-1128.

22. Evans DK, Miguel E. Orphans and schooling in Africa: a longitudinal analysis. Demography. 2007; 44, 35-57.

23. Kobiané JF, Calvès AE, Marcoux R. Parental death and children's schooling in Burkina Faso. Comp Educ Rev. 2005; 49, 468-489.

24. Fleisch B, Shindler J. Gender repetition: school access, transitions and equity in the 'Birth to Twenty' cohort panel study in urban South Africa. Comp Educ. 2009; 45, 265-279.
25. Motala S, Dieltiens V, Sayed Y. Physical access to schooling in South Africa: mapping dropout, repetition and age-grade progression in two districts. Comp Educ. 2009; 45, 251-263.

26. De Neve J-W, Fink G, Subramanian SV, Moyo S, Bor J. Length of secondary schooling and risk of HIV infection in Botswana: evidence from a natural experiment. Lancet Glob Health. 2015; 3, 470-477.

27. Zaidi J, Grapsa E, Tanser F, Newell M-L, Bärnighausen T. Dramatic increases in HIV prevalence after scale-up of antiretroviral treatment: a longitudinal population-based HIV surveillance study in rural kwazulu-natal. AIDS. 2013; 27, 2301-2305.

28. Houlihan CF, Bland RM, Mutevedzi PC, et al. Cohort profile: Hlabisa HIV treatment and care programme. Int J Epidemiol. 2011; 40, 318-326.

29. Mkwanazi NB, Patel D, Newell M-L, et al. Rapid testing may not improve uptake of HIV testing and same day results in a rural South African community: a cohort study of 12,000 women. PLoS One. 2008; 3, 3501.

30. Bland R, Coovadia H, Coutsoudis A, Rollins N, Newell M. Cohort profile: mamanengane or the Africa centre vertical transmission study. Int J Epidemiol. 2010; 39, 351-360.

31. Coovadia HM, Rollins NC, Bland RM, et al. Mother-to-child transmission of HIV-1 infection during exclusive breastfeeding in the first 6 months of life: an intervention cohort study. Lancet. 2007; 369, 1107-1116.

32. Galobardes B, Shaw M, Lawlor DA, Lynch JW. Indicators of socioeconomic position (part 1). J Epidemiol Commun H. 2006; 60, 7-12.

33. Achenbach TM, Edelbrock CS. Manual for the Child Behavior Checklist and Revised Child Behavior Profile. 1983. University of Vermont: Burlington.

34. Bangirana $\mathrm{P}$, Seggane-Musisi $\mathrm{P}$, Allebeck $\mathrm{P}$, et al. A preliminary examination of the construct validity of the KABC-II in Ugandan children with a history of cerebral malaria. Afr Health Sci. 2009; 9, 186-192.

35. Malda M, van de Vijver FJ, Srinivasan K, Transler C, Sukumar P. Traveling with cognitive tests: testing the validity of a KABC-II adaptation in India. Assessment. 2009; 17, 107-115.

36. Organization WH. Global Strategy for Infant and Young Child Feeding, 2003. World Health Organisation: Geneva, Switzerland.

37. Corporation S. Stata Statistical Software: Release 13, 2013. StataCorp LP: College Station, TX.

38. Hsieh H-F, Shannon SE. Three approaches to qualitative content analysis. Qual Health Res. 2005; 15, 1277-1288.

39. Anderson KG, Case A, Lam D. Causes and consequences of schooling outcomes in South Africa: evidence from survey data. Soc Dynamics. 2001; 27, 37-59.

40. Hungi $\mathrm{N}$. What are the levels and trends in grade repetition. SACMEQ policy issues series, number 5 2010. Retrieved 24th August 2015 from http://www.sacmeq.org/sites/default/files/ sacmeq/reports/sacmeq-iii/policy-issue-series/005sacmeqpolicyissuesseries-graderepetition.pdf.

41. Ginsburg C, Richter LM, Fleisch B, Norris SA. An analysis of associations between residential and school mobility and educational outcomes in South African urban children: the Birth to twenty cohort. Int J Educ Dev. 2011; 31, 213-222.

42. Voyer D, Voyer SD. Gender differences in scholastic achievement: a meta-analysis. Psychol Bull. 2014; 140, 1174-1204. 
43. Liddell C, Rae G. Predicting early grade retention: a longitudinal investigation of primary school progress in a sample of rural South African children. Brit J Educ Psychol. 2001; 71, 413-428.

44. Case A, Paxson C, Ableidinger J. Orphans in Africa: parental death, poverty, and school enrollment. Demography. 2004; 41, 483-508.

45. Nyirenda M, McGrath N, Newell M-L. Gender differentials in the impact of parental death: adolescent's sexual behaviour and risk of HIV infection in rural South Africa. Vulnerable Child Youth Stud. 2010; 5, 284-296.

46. Bicego G, Rutstein S, Johnson K. Dimensions of the emerging orphan crisis in sub-Saharan Africa. Soc Sci Med. 2003; 56, 1235-1247.

47. Downey DB. Number of siblings and intellectual development: the resource dilution explanation. Am Psychol. 2001; 56, 497-504.

48. Rudasill KM, Rimm-Kaufman SE. Teacher-child relationship quality: the roles of child temperament and teacher-child interactions. Early Child Res Q. 2009; 24, 107-120.

49. King EM. The effect of family size on family welfare: what do we know?. In Population Growth And Economic Development: Issues and Evidence (eds. Johnson D, Lee R), 1987; pp. 373-411. University of Wisconsin Press: Wisconsin.

50. Cockburn J, Dostie B. Child work and schooling: the role of household asset profiles and poverty in rural Ethiopia. J Afr Econ. 2007; 16, 519-563.

51. Maharaj P, Kaufman C, Richter L. Children's Schooling In South Africa: Transitions And Tensions In Households and Communities. CSDS Working Paper 30. 2000. University of Natal: Durban.

52. Niehaus IA. Disharmonious spouses and harmonious siblings: conceptualising household formation among urban residents in Qwaqwa. Afr Stud. 1994; 53, 115-135.

53. Cicirelli VG. Sibling relationships in cross-cultural perspective. J Marriage Fam. 1994; 56, 69-85.

54. Soudien C. 'Constituting the class': an analysis of the process of 'integration' in South African schools. In Changing class: Education and Social Change in Post-Apartheid South Africa (ed. Chisholm L), 2004; 89-114. HSRC Press: Cape Town.

55. Glick P, Sahn DE. Schooling of girls and boys in a West African country: the effects of parental education, income, and household structure. Econ Educ Rev. 2000; 19, 63-87.

56. Case A, Ardington C. The impact of parental death on school outcomes: longitudinal evidence from South Africa. Demography. 2006; 43, 401-420.
57. Orkin M, Boyes ME, Cluver LD, Zhang Y. Pathways to poor educational outcomes for HIV/AIDS-affected youth in South Africa. AIDS Care. 2014; 26, 343-350.

58. Foster G, Williamson J. A review of current literature on the impact of HIV/AIDS on children in sub-Saharan Africa. AIDS. 2000; 14, 275-284.

59. Robson E. Invisible carers: young people in Zimbabwe's home-based healthcare. Area. 2000; 32, 59-69.

60. Cluver LD, Orkin FM, Boyes ME, Sherr L. Cash plus care: social protection cumulatively mitigates HIV-risk behaviour among adolescents in South Africa. AIDS. 2014; 28, S389-S397.

61. Wamani H, Åstrøm AN, Peterson S, Tumwine JK, Tylleskär T. Boys are more stunted than girls in sub-Saharan Africa: a meta-analysis of 16 demographic and health surveys. BMC Pediatr. 2007; 7, 17.

62. Edmonds EV. Child labor and schooling responses to anticipated income in South Africa. J Dev Econ. 2006; 81, 386-414.

63. Mashiya N. IsiZulu and English in KwaZulu-Natal rural schools: how teachers fear failure and opt for English. South African J Childhood Educ. 2014; 1, 19-31.

64. Lehr CA, Sinclair MF, Christenson SL. Addressing student engagement and truancy prevention during the elementary school years: a replication study of the check \& connect model. JESPAR. 2004; 9, 279-301.

65. van Breda M. Acting up or opting out: an analytical literature review of extant South African and international school truancy studies. Mediterr J Soc Sci. 2014; 5, 322.

66. Hill NE, Tyson DF. Parental involvement in middle school: a meta-analytic assessment of the strategies that promote achievement. Dev Psychol. 2009; 45, 740-763.

67. Siziya S, Muula AS, Rudatsikira E. Prevalence and correlates of truancy among adolescents in Swaziland: findings from the Global School-Based Health Survey. Child Adolesc Psychiatry Ment Health. 2007; 1, 15.

68. van Breda MJ. Truants' perceptions of family factors as causes of school truancy and non-attendance. J Psychol. 2014; 5, 47-53.

69. Welsh JA, Nix RL, Blair C, Bierman KL, Nelson KE. The development of cognitive skills and gains in academic school readiness for children from low-income families. J Educ Psychol. $2010 ; 102,43-53$. 